\title{
Nutrition, exercise and the immune system
}

\author{
Bente Klarlund Pedersen*, Kenneth Ostrowski, Thomas Rohde and Helle Bruunsgaard \\ The Copenhagen Muscle Research Centre, Department of Infectious Diseases, Rigshospitalet, University of Copenhagen, \\ Copenhagen, Denmark
}

Today epidemiological evidence exists which supports the anecdotal impression (Nieman \& Henson, 1994) that regular exercise increases resistance to infections such as the common cold (Nash, 1987; Fitzgerald, 1988), whereas hard training is associated with increased respiratory infections (Fitzgerald, 1988). It has become clear that the function of the immune system is enhanced by moderate physical activity and may be somewhat responsible for exercise-related reduction in illness. In contrast, it has been repeatedly shown that intense exercise causes inhibition of the function of the immune system in the recovery phase following intense exercise (Hoffman-Goetz \& Pedersen, 1994).

Today, much research in exercise immunology is stimulated by the acceptance of exercise as a tool to study the immune system. Exercise can be employed as a model for temporary immunosuppression, which occurs after severe physical stress. Furthermore, exercise associated with muscle damage represents a model of the acute-phase response to local injury. Given the fact that nutrition is a critical determinant of immunocompetence, the potential protective role of nutritional agents in exercise-induced immunosuppression will be discussed.

\section{Acute exercise and the cellular immune system}

In relation to acute exercise there are several consistent patterns that emerge regarding leucocyte subpopulations in the blood. The neutrophil concentration increases during exercise and continues to increase post-exercise (McCarthy \& Dale, 1988). The lymphocyte concentration increases during exercise and falls below pre-exercise values following intense long-duration exercise, but is not suppressed after moderate exercise (McCarthy \& Dale, 1988). The increased lymphocyte concentration is due to recruitment of all lymphocyte subpopulations to the blood. Thus, the CD4 + T cells, CD8 + T cells, CD19+ B cells, CD16 + natural killer (NK) cells and CD56 + NK cells increase in number during exercise and decline following intense exercise lasting at least $1 \mathrm{~h}$. Furthermore, following intense long-duration exercise the functions of NK and B cells are suppressed. Thus, the NK cell activity (the ability of NK cells to lyse a certain number of tumour target cells) is inhibited. Furthermore, antibody production in the circulation is inhibited and the local production of secretory immunoglobulin A in mucosa is inhibited (Pedersen, 1997).

\section{Acute exercise and cytokine production}

Cytokines are a group of low-molecular-weight regulatory proteins secreted by leucocytes and a variety of other cells in the body in response to a number of inducing stimuli. In the acute-phase response, interleukin (IL)-1, IL-6 and tumour necrosis factor (TNF)- $\alpha$ have been most extensively studied. Although the initial studies thus showed that systemic elevations of cytokines occur in serum after strenuous exercise, the identity of the observed cytokine was uncertain. Although IL-1 was believed to be the cytokine responsible for the exercise-induced plasma activities described by Cannon \& Kluger (1983), Cannon et al. (1986) and Evans et al. (1986), the possibility exists that other cytokines were also present since the latter studies were conducted before the availability of recombinant IL-1 proteins. As pointed out by Bagby et al. (1996) there have been a number of studies which failed to detect significantly elevated levels of IL-1 in plasma (Cannon et al. 1991; Northoff \& Berg, 1991; Sprenger et al. 1992; Ullum et al. 1994). However, IL-6 was enhanced in studies by Northof \& Berg (1991), Ullum et al. (1994), Sprenger $e t$ al. (1992), Bruunsgaard et al. (1997) and in two studies by Rohde and co-workers (T Rohde, DA MacLean and BK Pedersen, unpublished results; T Rohde, S Asp, DA MacLean and BK Pedersen, unpublished results).

Bruunsgaard et al. (1997) performed a study to test the hypothesis that the exercise-induced increase in cytokine levels was associated with muscle damage. Healthy young males performed two periods of bicycle exercise; the first trial consisted of $30 \mathrm{~min}$ concentric exercise, whereas the second consisted of $30 \mathrm{~min}$ eccentric exercise. In eccentric exercise the quadriceps muscles are forced to lengthen during tension development. This was achieved when the direction of revolution was reversed and the subjects were thus opposing the rotation of the pedals. The creatine kinase (EC 2.7.3.2) level had increased almost 50-fold at $4 \mathrm{~d}$ after eccentric exercise, whereas there were no changes in creatine kinase level after concentric exercise. The IL-6 level had increased 5-fold at $2 \mathrm{~h}$ after eccentric exercise, but

\footnotetext{
Abbreviations: IL, interleukin; NK, natural killer; PG, prostaglandin; TNF, tumour necrosis factor; URTI, upper respiratory tract infections.

*Corresponding author: Dr B. K. Pedersen, fax 00453545 6648, email bkp@
} 
not after concentric exercise. Thus, the study supports the hypothesis that the post-exercise cytokine production is related to skeletal muscle damage. Recently, we have found a 50-fold increase in plasma levels of IL-6 and increased levels of IL-1-receptor antagonist following a marathon (T Rohde, K Ostrowski, M Zacho, S Asp and BK Pedersen, unpublished results). Thus, several studies have identified an exercise-induced increase in IL-6 activity in response to exercise. A significant correlation was found between IL-6 $2 \mathrm{~h}$ after exercise and the creatine kinase level in the days following exercise $(r 0.722, P=0.028)$ (Bruunsgaard $e t$ al. 1997).

\section{Upper respiratory tract infections after exercise}

It has been demonstrated in a number of studies that resting levels of the immune system are not impaired in trained $v$. untrained subjects (for recent review, see Nieman, 1996). However, based on anecdotal information the general consensus has been that while regular training promotes resistance to upper respiratory tract infections (URTI), severe exertion, especially when coupled with mental stress, places athletes at increased risk of URTI (Fitzgerald, 1991; Nieman, 1994a).

Peters \& Bateman (1983) carried out a prospective study of the incidence of symptoms of URTI in 150 randomlyselected runners who took part in the 1982 Two Oceans Marathon in Cape Town, and compared this with the incidence in individually-matched controls who did not run. Runners were questioned on the day before and 2 weeks after the race. Symptoms of URTI occurred in $33.3 \%$ of runners compared with $15.3 \%$ of controls, and were most common in those who achieved the faster race times. Nieman et al. (1989) studied the incidence of infectious episodes in 273 runners during a 2 -month training period before a $5 \mathrm{~km}, 10 \mathrm{~km}$ or half-marathon race. In addition, the effect of the race experience on infectious episodes was studied. Only $6.8 \%$ of the runners preparing for the halfmarathon race reported becoming sick $v .17 .95 \%$ of the $5 \mathrm{~km}$ and $10 \mathrm{~km}$ runners $(P=0.067)$. This study thus showed a trend that runners with a more serious commitment to regular exercise had fewer infectious episodes.

The largest epidemiological study on exercise and URTI was performed by Nieman et al. (1990a) who investigated the incidence of URTI in a group of 2311 marathon runners who took part in the 1987 Los Angeles Marathon race. It was found that $12.9 \%$ of Los Angeles Marathon participants reported an infectious episode during the week following the race in comparison with only $2.2 \%$ of similarly-experienced runners who had applied but did not participate (for reasons other than sickness). Controlling for important demographic and training data by using logistic regression, it was determined that the odds were $6: 1$ in favour of sickness for the marathon-race participants $v$. the non-participating runners.

There is a lack of studies comparing URTI in large groups of moderately-active individuals. However, two randomized experimental trials using small numbers of subjects have provided important data in support of the viewpoint that moderate physical activity may reduce
URTI symptomatology. A study of thirty-six women who performed a 15-week walking programme (45 min of walking, on $5 \mathrm{~d}$ per week) reported significantly fewer days with URTI symptoms during the 15-week study than the control group $(5.1 v \cdot 10.8 \mathrm{~d})$. The number of separate URTI did not vary between groups, but the number of URTI symptom days per incident was lower in the exercising group (Nieman et al. 1990b). In a randomized, controlled study of elderly women, 67-85 years of age, the incidence of the common cold during a 12-week period in the autumn was found to be the lowest in highlyconditioned subjects who exercised moderately each day for about $1.5 \mathrm{~h}(8 \%)$, elderly subjects who walked for $40 \mathrm{~min}$ five times weekly had an incidence of $21 \%$, compared with $50 \%$ for the sedentary control group (Nieman et al. 1993). This study clearly showed that elderly women not engaging in cardio-respiratory exercise are more likely to experience an URTI during the autumn than those who do exercise regularly.

Based on the previously-mentioned epidemiological studies a relationship between exercise and URTI has been modelled in the form of a ' $\mathrm{J}$ ' curve. This model suggests that while the risk of URTI may decrease below that of a sedentary individual when engaging in moderate exercise training, the risk may rise above average during periods of excessive high-intensity exercise (Nieman, 1994b).

\section{Nutritional aspects of exercise and immune function}

\section{Antioxidants}

Intervention studies have been carried out based on a theory that competitive distance running results in alterations in the hormonal milieu which, in turn, affects free-radical production rates and, hence, immunological function. Antioxidants may, in theory, neutralize the reactive species which are produced by neutrophilic leucocytes during phagocytosis (Babior, 1984; Hemila, 1992). It is generally accepted that ascorbate is the predominant antioxidant in the blood and interstitial fluids, and that its primary target in promoting immunocompetence appears to be the phagocyte, particularly the neutrophil (Anderson \& Lukey, 1987).

Using a double-blind placebo design, Peters et al. (1993) evaluated the effect of vitamin C on the incidence of URTI during the 2-week period following the $90 \mathrm{~km}$ Comrades Ultramarathon. The URTI incidence was $68 \%$ in the placebo group, which was significantly more than that in the group receiving the vitamin $\mathrm{C}$ supplement, in which only $33 \%$ reported URTI when taking a $600 \mathrm{mg}$ vitamin C supplement daily for 3 weeks before the race. In another study Peters et al. (1992) found that vitamin A supplementation did not have a significant effect on the incidence of URTI in marathon runners.

Interesting studies on the influence of vitamin $E$ on exercise-induced neutrophilia and the acute-phase response have been performed by Cannon et al. $(1990,1991)$. The changes in circulating neutrophils in young (22-29 years) and older (55-74 years) men in response to $45 \mathrm{~min}$ of downhill running exercise were investigated. In the young subjects, circulating neutrophils rose after exercise, reaching peak levels after $6 \mathrm{~h}$, and the response was unaffected 
by vitamin E supplementation. However, in older subjects, vitamin $\mathrm{E}$ diminished the post-exercise rise in circulating neutrophils (Cannon et al. 1990). The same group investigated the influence of damaging eccentric exercise on in vitro production and plasma concentrations of cytokines and their relationship to muscle breakdown. In a double-blind placebo-controlled study they examined the effect of vitamin $\mathrm{E}$ supplementation for $48 \mathrm{~h}$ on the exercise-induced acute-phase response. The volunteers were either young (average age 25 years) or elderly (average age 65 years) sedentary men. They performed $45 \mathrm{~min}$ of eccentric exercise (downhill treadmill). At $24 \mathrm{~h}$ after this single session of eccentric exercise, endotoxininduced secretion of IL- $1 \beta$ was augmented in cells obtained from the placebo subjects, but no significant changes were observed in cells from the vitamin E-supplemented subjects (Cannon et al. 1991).

The finding by Cannon et al. (1991) that IL-1 $\beta$ and TNF $\alpha$ secretion was increased the morning after exercise without any current changes in mononuclear cell numbers indicates that the monocytes are activated in relation to eccentric exercise. The effect of vitamin E on IL- $1 \beta$ and IL-6 could not be ascribed to changes in prostaglandin (PG) $E_{2}$ (Cannon et al. 1991). Oxygen radicals enhance endotoxininduced IL-1 production (Kasama et al. 1989). Furthermore, the concentrations of these reactants increase with exercise (Davies et al. 1982). Thus, the effect of vitamin E on the secretion of IL- $1 \beta$ is consistent with a mechanism involving oxygen radicals. No studies have measured the influence of antioxidants on plasma cytokines, which may be a better reflection of the in vivo situation. In our opinion, it is still premature to conclude that antioxidants as such have a significant impact on exercise-induced immunomodulation or acute-phase response in relation to exercise.

\section{Lipids}

It has been suggested that if the ratio $n-6: n-3$ fatty acids is shifted in favour of $n-6$ fatty acids, this will result in increased production of $\mathrm{PGE}_{2}$; thereby, the cellular immune system will be suppressed. During stress conditions, $n-3$ fatty acids may counteract the latent immunosuppression mediated by increasing $\mathrm{PGE}_{2}$ production (from $n-6$ fatty acids), which in contrast appears to be further enhanced by intake of $n-6$ fatty acids. Under the condition of hypermetabolism, $n-3$ fatty acids, therefore, potentially act to reduce the incidence of new infections. In animal experiments it was shown that the stress response following application of endotoxin, IL-1 or TNF was reduced when the animals were pretreated with $n-3$ fatty acids (fish oil). The diet rich in $n-3$ fatty acids caused reduced catabolism, reduced febrile reaction, decreased eicosanoid production and improved survival rate (Johnson et al. 1993).

The possible interaction between intense acute exercise, known to suppress the immune system (Hoffman-Goetz \& Pedersen, 1994), and polyunsaturated fatty acids was examined in inbred female C57BI/6J mice (Benquet et al. 1994). The animals received either a natural-ingredient diet or a diet supplemented with various oils such as beef tallow, safflower oil, fish oil or linseed oil for an 8-week period. In the group receiving $18: 3 n-3$ linseed oil it was shown that linseed oil abolished post-exercise immunosuppression of the immunoglobulin $\mathrm{M}$ plaque-forming cell response. The mechanism underlying the absence of exercise-induced immunosuppression in animals fed on linseed oil may be that linseed oil diminishes $n-6: n-3$ and, hence, diminishes the $\mathrm{PGE}_{2}$ level after intense exercise. Thus, the PG-mediated immunosuppression may be abolished.

The effect of linseed oil may be ascribed, therefore, to a link between a diet rich in $n-3$ polyunsaturated fatty acids and abolishment of PG-related immunosuppression. In support of this hypothesis, it has been shown that when $\mathrm{PGE}_{2}$ production was inhibited by the PG-inhibitor indomethacin, exercise-induced suppression of the NK cell activity and B cell function was partly abolished (Tvede $e t$ al. 1989; Pedersen et al. 1990). The possibility that $n-3$ fatty acids may diminish the exercise-induced cytokine response has not been investigated and there are no published human exercise studies evaluating the role of lipids in abolishing post-exercise immunosuppression.

\section{Glutamine}

It has been accepted generally that cells of the immune system obtain their energy by metabolism of glucose. However, it has been established that glutamine is also an important fuel for lymphocytes and macrophages. Several lines of evidence suggest that glutamine is used at a very high rate by these cells, even when they are quiescent (Newsholme, 1994). It has been proposed that the glutamine pathway in lymphocytes may be under external regulation, due partly to the supply of glutamine itself (Ardawi \& Newsholme, 1984).

Skeletal muscle is the major tissue involved in glutamine production and is known to release glutamine into the bloodstream at a high rate. It has been suggested that the skeletal muscle plays a vital role in maintenance of the key process of glutamine utilization in the immune cells. Consequently, the activity of the skeletal muscle may directly influence the immune system. It has been hypothesized (the so-called 'glutamine-hypothesis') that under intense physical exercise, or in relation to surgery, trauma, burn and sepsis, the demands on muscle and other organs for glutamine is such that the lymphoid system may be forced into a glutamine debt, which temporarily affects its function. Thus, factors that directly or indirectly influence glutamine synthesis or release could, theoretically, influence the function of lymphocytes and monocytes (Newsholme, 1990, 1994). Following intense long-term exercise and other physical-stress disorders, the glutamine concentration in plasma declines (Essen et al. 1992; Parry Billings et al. 1992; Keast et al. 1995; Lehmann et al. 1995).

Clearly, optimal lymphocyte proliferation is dependent on the presence of glutamine, but there are no published data showing that glutamine supplementation restores impaired immune function post-exercise. The critical question, therefore, is not whether concomitant decreased plasma glutamine concentration and lymphocyte function 
occur following intense exercise, but whether a causal relationship exists. Two recent placebo-controlled glutamine intervention studies (T Rhode, DA MacLean and BK Pederson, unpublished results; T Rhode, S Asp, DA MacLean and BK Pederson, unpublished results) showed that the post-exercise decline in plasma glutamine was abolished without influencing post-exercise immunosuppression. Thus, these studies do not support the hypothesis that post-exercise immunosuppression is caused by a decrease in the plasma glutamine concentration.

\section{Post-exercise immunosuppression and nutritional factors}

In essence, the immune system is enhanced during moderate and severe exercise, and only intense longduration exercise is followed by immunodepression, which includes suppressed concentrations of lymphocytes, suppressed NK cell activity and reduced production of secretory immunoglobulin A in mucosa. During the period of immunodepression referred to as 'the open window', pathogenic agents, especially viruses, may invade the host and infections may be established. One reason for the 'overtraining effect' seen in elite athletes could be that this window of opportunism for pathogens is longer and the degree of immunosuppression more pronounced.

Clearly, the mechanisms underlying exercise-induced immunomodulation are multi-factorial and include neuroendocrine, physiological and metabolic factors (Pedersen $e t$ al. 1996). It is easily understood, therefore, that it has not been possible to identify one single nutrient factor which is capable of abolishing post-exercise immunosuppression.

\section{Acknowledgement}

The work was supported by The National Research Foundation grant no. 504-14.

\section{References}

Anderson R \& Lukey PT (1987) A biological role for ascorbate in the selective neutralization of extracellular phagocyte-derived oxidants. Annals of the New York Academy of Sciences 498, 229-247.

Ardawi MS \& Newsholme EA (1984) Intracellular localization and properties of phosphate-dependent glutaminase in rat mesenteric lymph nodes. Biochemical Journal 217, 289-296.

Babior BM (1984) Oxidants from phagocytes: agents of defense and destruction. Blood 64, 959-966.

Bagby GJ, Crouch LD \& Shepherd RE (1996) Exercise and cytokines: Spontaneous and elicited response. In Exercise and Immune Function, pp. 55-78 [L Hoffman-Goetz, editor]. New York: CRC Press.

Benquet C, Krzystyniak K, Savard R \& Guertin F (1994) Modulation of exercise-induced immunosuppression by dietary polyunsaturated fatty acids in mice. Journal of Toxicology and Environmental Health 43, 225-237.

Bruunsgaard H, Galbo H, Halkjaer-Kristensen J, Johansen TL, MacLean DA \& Pedersen BK (1997) Exercise-induced increase in interleukin-6 is related to muscle damage. Joumal of Physiology 499, 833-841.

Cannon JG, Evans WJ, Hughes VA, Meredith CN \& Dinarello CA (1986) Physiological mechanisms contributing to increased interleukin-1 secretion. Journal of Applied Physiology 61, 1869-1874.

Cannon JG \& Kluger MJ (1983) Endogenous pyrogen activity in human plasma after exercise. Science 220, 617-619.

Cannon JG, Meydani SN, Fielding RA, Fiatarone MA, Meydani M, Farhangmehr M, Orencole SF, Blumberg JB \& Evans WJ (1991) Acute phase response in exercise. II. Associations between vitamin E, cytokines, and muscle proteolysis. American Journal of Physiology 260, R1235-R1240.

Cannon JG, Orencole SF, Fielding RA, Meydani M, Meydani SN, Fiatarone MA, Blumberg JB \& Evans WJ (1990) Acute phase response in exercise: interaction of age and vitamin $\mathrm{E}$ on neutrophils and muscle enzyme release. American Journal of Physiology 259, R1214-R1219.

Davies KJA, Packer L \& Brooks GA (1982) Free radicals and tissue produced by exercise. Biochemical and Biophysical Research Communications 107, 1198-1205.

Essen P, Wernerman J, Sonnenfeld T, Thunell S \& Vinnars E (1992) Free amino acids in plasma and muscle during 24 hours post-operatively - a descriptive study. Clinical Physiology 12, 163-177.

Evans WJ, Meredith CN, Cannon JG, Dinarello CA, Frontera WR, Hughes VA, Jones BH \& Knuttgen HG (1986) Metabolic changes following eccentric exercise in trained and untrained men. Journal of Applied Physiology 61, 1864-1868.

Fitzgerald L (1988) Exercise and the immune system. Immunology Today $9,337-339$.

Fitzgerald L (1991) Overtraining increases the susceptibility to infection. International Joumal of Sports Medicine 12, S5-S8.

Hemila H (1992) Vitamin C and the common cold. British Joumal of Nutrition 67, 3-16.

Hoffman-Goetz L \& Pedersen BK (1994) Exercise and the immune system: a model of the stress response? Immunology Today 15, 382-387.

Johnson JA III, Griswold JA \& Muakkassa FF (1993) Essential fatty acids influence survival in sepsis. Journal of Trauma 35, 128-131.

Kasama TK, Kobayashi T, Fukushima M, Tabata M, Ohno I, Negishi M, Ide H, Takahashi T \& Niwa Y (1989) Production of interleukin 1-like factor from human peripheral blood monocytes and polymorphonuclear leukocytes by superoxide anion: the role of interleukin 1 and reactive oxygen species in inflamed sites. Immunology and Immunopathology 53, 439-448.

Keast D, Arstein D, Harper W, Fry RW \& Morton AR (1995) Depression of plasma glutamine concentration after exercise stress and its possible influence on the immune system. Medical Journal of Australia 162, 15-18.

Lehmann M, Huonker M, Dimeo F, Heinz N, Gastmann U, Treis N, Steinacker JM, Keul J, Kajewski R \& Haussinger D (1995) Serum amino acid concentrations in nine athletes before and after the 1993 Colmar ultra triathlon. International Journal of Sports Medicine 16, 155-159.

McCarthy DA \& Dale MM (1988) The leucocytosis of exercise. A review and model. Sports Medicine 6, 333-363.

Nash HL (1987) Can exercise make us immune to disease? Physician and Sports Medicine 250-253.

Newsholme EA (1990) Psychoimmunology and cellular nutrition: an alternative hypothesis (editorial). Biological Psychiatry 27, 1-3.

Newsholme EA (1994) Biochemical mechanisms to explain immunosuppression in well-trained and overtrained athletes. International Journal of Sports Medicine 15, Suppl. 3, S142S147. 
Nieman DC (1994a) Exercise, infection, and immunity. International Journal of Sports Medicine 15, Suppl. 3, S131-\$141.

Nieman DC (1994b) Exercise, upper respiratory tract infection, and the immune system. Medicine and Science in Sports and Exercise 26, 128-139.

Nieman DC (1996) Prolonged aerobic exercise, immune response, and risk of infection. In Exercise and Immune Function, pp. 143-162 [L Hoffman-Goetz, editor]. New York: CRC Press.

Nieman DC \& Henson DA (1994) Role of endurance exercise in immune senescence. Medicine and Science in Sports and Exercise 26, 172-181.

Nieman DC, Henson DA, Gusewitch G, Warren BJ, Dotson RC, Butterworth DE \& Nehlsen Cannarella SL (1993) Physical activity and immune function in elderly women. Medicine and Science in Sports and Exercise 25, 823-831.

Nieman DC, Johanssen LM \& Lee JW (1989) Infectious episodes in runners before and after a roadrace. Journal of Sports Medicine and Physical Fitness 29, 289-296.

Nieman DC, Johanssen LM, Lee JW \& Arabatzis K (1990a) Infectious episodes in runners before and after the Los Angeles Marathon. Journal of Sports Medicine and Physical Fitness 30, 316-328.

Nieman DC, Nehlsen Cannarella SL, Markoff PA, Balk Lamberton AJ, Yang H, Chritton DB, Lee JW \& Arabatzis K $(1990 b)$ The effects of moderate exercise training on natural killer cells and acute upper respiratory tract infections. International Journal of Sports Medicine 11, 467-473.

Northoff H \& Berg A (1991) Immunologic mediators as parameters of the reaction to strenuous exercise. International Journal of Sports Medicine 12, S9-S15.

Parry Billings $\mathbf{M}$, Budgett $\mathbf{R}$, Koutedakis $\mathrm{Y}$, Blomstrand E, Brooks S, Williams C, Calder PC, Pilling S, Baigrie R \& Newsholme EA (1992) Plasma amino acid concentrations in the overtraining syndrome: possible effects on the immune system. Medicine and Science in Sports and Exercise 24, 1353-1358.
Pedersen BK (1997) Exercise Immunology, pp. 1-206. Austin, TX: R. G. Landes Bioscience.

Pedersen BK, Bruunsgaard H, Klokker M, Kappel M, MacLean DA, Nielsen HB, Rohde T, Ullum H \& Zacho M (1996) Exercise-induced immunomodulation-possible roles of neuroendocrine factors and metabolic factors. International Journal of Sports Medicine 18, S2-S7.

Pedersen BK, Tvede N, Klarlund K, Christensen LD, Hansen FR, Galbo H, Kharazmi A \& Halkjaer Kristensen J (1990) Indomethacin in vitro and in vivo abolishes post-exercise suppression of natural killer cell activity in peripheral blood. International Journal of Sports Medicine 11, 127-131.

Peters EM \& Bateman ED (1983) Ultramarathon running and upper respiratory tract infections: An epidemiological survey. South African Medical Journal 64, 582-584.

Peters EM, Cambell A \& Pawley L (1992) Vitamin A fails to increase resistance to upper respiratory tract infection in distance runners. South African Journal of Sports Medicine 7, 3-7.

Peters EM, Goetzsche JM, Grobbelaar B \& Noakes TD (1993) Vitamin $\mathrm{C}$ supplementation reduces the incidence of postrace symptoms of upper-respiratory-tract infection in ultramarathon runners. American Journal of Clinical Nutrition 57, 170-174.

Sprenger H, Jacobs C, Nain M, Gressner AM, Prinz H, Wesemann W \& Gemsa D (1992) Enhanced release of cytokines, interleukin-2 receptors, and neopterin after long-distance running. Clinical Immunology and Immunopathology 63, 188195.

Tvede N, Heilmann C, Halkjaer Kristensen J \& Pedersen BK (1989) Mechanisms of B-lymphocyte suppression induced by acute physical exercise. Journal of Clinical Laboratory Immunology 30, 169-173.

Ullum H, Haahr PM, Diamant M, Palmo J, Halkjaer Kristensen J \& Pedersen BK (1994) Bicycle exercise enhances plasma IL-6 but does not change IL $1 \alpha$, IL $1 \beta$, IL-6, or TNF- $\alpha$ pre-mRNA in BMNC. Journal of Applied Physiology 77, 93-97. 